\title{
Using comics-based representations of teaching, and technology, to bring practice to teacher education courses
}

Patricio Herbst,1,2 Daniel Chazan, Chia-Ling Chen, Vu-Minh Chieu, and Michael Weiss

\begin{abstract}
This article situates comic-based representations of teaching in the long history of tensions between theory and practice in teacher education. The article argues that comics can be semiotic resources in learning to teach and suggests how information technologies can support experiences with comics in university mathematics methods courses that a) help learners see the mathematical work of teaching in lessons they observe, b) allow candidates to explore tactical decision making in teaching, and c) support pre-service teachers in rehearsing classroom interactions.
\end{abstract}

\section{Introduction}

Teacher education, like other professional preparation done at the university, has long wrestled with tensions between theory and practice (e.g., Dewey, 1904; Schwab, 1959; Shulman, 1998). After introductory observations about theory and practice in teacher education, we consider how different genres of representations of teaching-written cases, videos, and comics-help bridge theory and practice. We describe how comics are useful semiotic resources for creating representations of teaching that capitalize on the advantages of written cases and video. Finally we describe how we have used comics to create representations of teaching usable in teacher preparation, the kinds of activities in teacher preparation that they can support, and the kind of technology that can make those activities possible.

\section{Evolving Relationships between Theory and Practice in Teacher Preparation}

At the turn of the twentieth century when teacher education, though soon to be the province of universities, was still the domain of the normal schools, John Dewey argued successfully for experience in schools for pre-service

${ }^{1}$ Corresponding author, University of Michigan, pgherbst@umich.edu.

${ }^{2}$ Work described in this paper has been done with support of NSF grant ESI0353285 to Herbst and Chazan. All opinions are those of the authors and do not represent the views of the Foundation. 
teacher candidates. But, while he valued experience in schools, he argued for a laboratory, rather than an apprenticeship, approach to these experiences (Dewey 1904). As Lee Shulman (1998) tells it,

Dewey mounts a vigorous attack on the technically oriented design of an apprenticeship model of teacher education. He associates this approach with the typical and traditional normal school, intent on producing skilled classroom managers and disciplinarians who will uncritically continue traditional practices (p. 514).

Writing at the end of the twentieth century and following contemporary developments on cognitive apprenticeship (Collins, Brown, \& Newman, 1989), Shulman is less negative on apprenticeship into teaching as a practice. Like Dewey, he maintains a view of theory as the realm of "universal terms" and of practice as situated in the "gritty particularities" (p. 519) of life. For him, following Aristotle, "theories are about essence, practice is about accident, and the only way to get from there to here is via the exercise of judgment" (p. 519). Shulman considers the role of practice in informing theory: "Lessons of practice must also find their ways back to the academy to inform, as well as to problematize, knowledge development in the academy itself" (p. 519). He closes by touting the pedagogical utility of cases:

As pedagogical devices, cases confront novice professionals with highly situated problems that draw together theory and practice in the moral sea of decisions to be made, actions to be taken. Options are rarely clean; judgments must be rendered. Cases are ways of parsing experience so practitioners can examine and learn from it. (p. 525)

In this article, we continue with Shulman's reappraisal of the value, for teacher educators, of viewing teaching as a practice. We follow his lead in examining the utility of representations of practice for teacher preparation, exploring new media that, we believe, offer such representations new potential in supporting learning to teach (Feiman-Nemser, 1983).

\subsection{Teaching mathematics as a practice}

Teaching mathematics, like other kinds of teaching, is a practice-a practice that includes representing mathematical knowledge for students to learn it, as well as assisting students in the process of learning such knowledge. Like other practices, it involves more than the application of technical knowledge expressed in declarative form in some disciplinary canon. There are forms of practical rationality (Herbst \& Chazan 2003; what Schön 1983, calls 'knowledge-in-action' and 'reflection-in-action') that enable practitioners to do what they do. Practitioners new to the practice must acquire a "feel for the game" (Bourdieu 1998, p. 25), or "knowledge without cognitive intent" (Bourdieu \& Wacquant 1992, p. 19). 
As an education in a practice, teacher preparation presupposes at the very minimum the development of capacity to reproduce such practice. More generally, as a professional preparation in a practice, teacher education presupposes the development of capacity to continuously improve the practice-making it more authentic, more efficient, more equitable. Teacher candidates need to study practice in order to reproduce it and to contribute to its improvement. Such preparation as typically organized in universities requires engagement in activities that are different than those employed in the study of academic disciplines: among those activities are the so-called "field experiences" and "methods" courses. Those experiences ordinarily serve to certify mathematics teachers educated at the university as professionals.

As Shulman (1998) argues, teachers have a domain of skilled performance or practice that is uniquely their own and obligations of service to others. Furthermore, they have the need for learning from experience, judgment under conditions of unavoidable uncertainty, as well as a professional community to monitor quality and aggregate knowledge. But, to call themselves professionals, mathematics teachers must also have understandings of a scholarly or theoretical kind that relate to their skills and judgment. Development of these sorts of understandings is the more typical province of the university, whether these understandings be mathematical content knowledge, or of adolescent development.

\subsection{The central role of time in practices}

Teacher educators experience tensions between theory and practice because the rationality of practice is different than that of disciplinary knowledge. Academic disciplines like mathematics are made of propositions that quite often aim at being timeless and coherent. Coherence within a field of knowledge is thus subject to strict logical analysis of available propositions. In elaborating on the logic of practice, Bourdieu (1990) emphasizes that such coherence is not of the same importance in practices; practitioners might engage in actions that, from an observer's perspective, might seem inconsistent-for example, saying one thing at one moment and the complete opposite at another.

Bourdieu explains away such seeming inconsistencies by remarking on a key element that characterizes practice: Time. Practices are made of actions that happen in time; their locations in time determine the spheres within which coherence is enforced. Erickson (2004) accordingly notes that time is involved in practice in at least two senses: On the one hand actions take time and occur at specific moments in time, on the other hand actions can be timely (or untimely), they depend on what happened before and constrain what can happen after. The latter element of this temporal distinction, the notion that it may (or may not) be the appropriate time for an action is key in interactive practices like teaching. It underscores that in order to reproduce and improve the practice of teaching, new practitioners need to learn not only about goals and strategies that warrant instances of practice but also 
about the possibilities and tactics that may be appropriate and viable at particular moments in those instances.

Returning to teacher education, to reproduce and improve practice, teachers need to know not only what is ordinarily done and what would be desirable to do instead, as well as why in general such actions are desirable, but also how and when to carry out these actions. Learning to teach for the purpose of reproducing and improving the practice, thus requires gaining a feel for the game, so to speak. Quite often teacher preparation has involved encounters not with practice but with knowledge about and ideologies for practice-for example in the form of descriptive statements about what teachers and students do, or prescriptive statements about what they should do (and in the extreme only proscriptive statements of what they should not do; Chazan \& Ball 1999). The encounter of teacher candidates with the doing of teaching has quite often been sidetracked to practica or internships in which little study of practice could be done (see also Lampert, 2010).

In this article, we argue that for beginners to encounter practice in ways that facilitate later reproduction and improvement, such learning to teach requires especially designed settings at the university. While traditionally those settings have been actual laboratory schools, or perhaps professional development schools (Holmes Group, 1990) progress in information technologies has enabled novel thinking about other settings that might also be useful. In this article we contribute to outline what an information technology (IT), or virtual, setting for learning to teach could look like (see also Chieu and Herbst, this issue). We concentrate in particular, on how an IT setting can help prospective teachers inquire and learn about the temporal and tactical work of teaching.

\section{Representing Practice: What might a knowledge base for teaching look like?}

Against the backdrop of a history of tensions between theory and practice in teacher education, as well as attempts to bridge them, one current focus is not only on developing a knowledge base for teaching, but also to invent ways to represent this knowledge base (e.g., see Hiebert, Gallimore, \& Stigler, 2002; Morris \& Hiebert, 2009). The question is what might such a knowledge base look like.

Researchers on teaching have demonstrated that teachers hold complex knowledge of the practice of teaching in the form of narratives and stories of instruction. The notion of story serves to give to teaching a rational organization, albeit a different one than the preferred by academic representations of knowledge of the disciplines. This rational organization takes into consideration the relevance of time in practice. Since teaching is a practice oriented to addressing particular problems, in particular contexts, and at particular times, it is reasonable that practitioners' craft knowledge be not only developed but also communicated and archived in the form of stories that help situate what is known in the midst of those circumstances 
(Brown et al., 2005; Carter 1993; Clandinin and Connelly, 1996; Leinhardt 1990).

For a long time that attention to the storied nature of teacher knowledge has been captured through the notion of "case." Cases have been a choice for the documentation of practical knowledge and for the practice of teacher education; it has taken the form of written cases or video.

Video records of instruction in real classrooms have been useful to bring to the fore the tactical, temporal demands of practice. Teacher education materials have been developed around the investigation of video records of practice (e.g., Seago, Mumme, and Branca 2004). Slate, a multimedia environment created by Lampert and Ball (1998) provides an early illustration of an IT setting for the study of the practice of instruction: It allowed beginning teachers to view video records of practice, annotate them, select clips, and assemble them into multimedia projects. More recently technologies like Video Paper Builder (Nemirovsky et al. 2005; Beardsley, et al. 2007), or LessonLab's Visibility platform (Santagata et al. 2007) have continued to enrich the set of tools with which teachers can experience and analyze available video records. There is an extensive literature that describes how engagement with videotaped episodes of teaching promotes the development of instructional capacity and important advances have been made to organize archives of video data and create experiences that permit teachers to view and comment on video (Fishman 2007; Sherin 2007). Video records of complex events featuring learning or teaching have been good for several activities in learning to teach, including identifying decision moments, justifying teacher choices, hypothesizing the conceptual basis of students' productions, and designing alternative teacher moves.

Written cases (Merseth 2003; Smith et al. 2004) have also been good to bring up the storied nature of teaching practice. In an effort to deploy more than action, but actually the deliberations and decisions that accompany action, written cases have often combined reports of what practitioners do with their reflections on what they see, how they interpret what they see, and how that fits with or requires realignment of purposes and strategies. Written cases have often been accompanied with materials that support their use in teacher education, such as activities and tasks in which a teacher educator could engage his or her students to work with the case.

Both video and written cases have been effective in directing attention to and enabling the study of practice; each of them has a legitimate place in the practice of teacher education. They are also different and a brief consideration of their differences may allow us to argue for other possible representations of teaching that may capture their advantages and supersede their disadvantages.

An important feature of video records of practice is that they contain rather thick depictions of the activity in focus: Not only do they show the actions of the teacher or students, but also they show how and when these are done in concert with other elements that constitute practice and that are happening 
in synchrony. Video records can immerse the viewer in a timeline and cadence very similar to that of the events recorded: The viewer can be engaged in the rhythm of events and develop sympathy with the characters in the record. Notwithstanding critiques of how reductive video records can be (Hall, 2000), video records also record more than practice, as in focus are often not just actions and the manner of doing them, but also individual features of the actors involved, some of which can be quite tangential to learning to teach mathematics. The sources of information can be all too real to the point that they discourage speculation by viewers who do not really know what had happened before, what was actually going on in the minds of teacher and students, or what personal circumstances afflicted them at the time the lesson took place.

In contrast written cases, like books in general, detach the user from the cadence of real events and give the user more control over the cadence in a completely different timescale, which results in the user having more time to stop and think. A written case may dwell on an action, freezing it in time while discussing motives and information states of the actors involved. While its temporal development may induce a different kind of sympathy with the events depicted than video records, a written case may also provide access to extra information not readily available for an observer (e.g., goals the teacher had or observations he or she made as students were working). By symbolizing action through language, a written case may also keep at bay some alternative sources of information, excluding in particular some of the individual features of the people involved (e.g., their dress style, body mass). Written cases or the images of student work that might accompany them can become useful props for speculation and discussion about possibilities. We take these considerations of advantages and disadvantages of video records and written cases as resources to define a set of attributes that we could expect any representation of practice to deliver on. ${ }^{3}$ Video records and written cases are two examples of what could be described more generally as a representation of teaching (see Grossman, Compton, Igra, Ronfeldt, Shahan, and Williamson, 2009).

The contrast offered above suggests two important variables that any representation of practice might instantiate and that are instantiated differently in video and written cases: Temporality and Individuality. The notion of temporality alludes to the sense to which a representation of teaching can more or less immerse the user in the timeline and cadence of the actions that make up the practice being studied. Along these lines a video record that plays without stop is on one end of the continuum while a written case that dwells at length on actions that took fractions of a second is on the other end. The notion of individuality alludes to the sense to which a representation of teaching can more or less individualize (or else symbolize) the characters and settings being represented. Along those lines a video record is very close to portraying characters and settings in their

\footnotetext{
${ }^{3}$ These characterizations are admittedly simple and for the sake of defining the following attributes. We realize that in actuality there are widely different ways of using each of those media forms, video or writing, to narrate practice.
} 
individuality (capturing nuances in voice pitch and hairstyle, while omitting scent or breath) and a written case symbolizes all of those with the choices of words but in general symbolizes only those attributes that are judged of relevance to the practice narrated. It is important for teacher education to have representations that contain such variation in considerations of temporality and individuality. More importantly, other representations are thinkable based on those considerations.

\subsection{Representing Practice with Comics}

We argue that comics with cartoon characters offer a semiotic resource that enables a high degree of control over the two dimensions of temporality and individuality, as well as over the possibility of creating alternatives, highlighting issues of tactical decision-making. McCloud (1993) defines comics as sequential art and classifies the genre in reference to the three poles of resemblance, picture plane, and meaning; his continuum between resemblance and meaning is what we've referred above as individuality.

When we think of comics as a semiotic resource for the practice of teaching, we include within it three canonical modes of representing time. The animation of cartoon characters with a voice over can mimic the temporality of video records, while providing choices for controlling how much individuality to show. The comic strip with speech or thought bubbles mimics the temporality of written cases and again offers a range of possibilities for individuality (from using photorealistic drawings to using stick figures). An intermediate case, the slide show with voice over or speech bubbles, can approach either end depending on whether controls over slide passing are programmed or left to the user.

The range of controls available to comics makes them especially useful for two kinds of purposes in representing teaching: representing scenarios that seldom exist and enabling the representation of alternative courses of action springing from a common trunk. These were particularly important purposes for project ThEMaT - Thought Experiments in Mathematics Teachingwhich explored the practical rationality ${ }^{4}$ of experienced teachers of algebra and geometry. The comics genre (realized as animations of cartoon characters) enabled us to create representations of teaching that could probe the rationality of practice by engaging practitioners in arguments about the feasibility of represented actions and about the value of alternative courses of action. Cartoons have allowed us to represent the same scenario for several "classes," or several scenarios in the same "class." They have allowed us to sketch a story that might be hard to come by in reality, and alternative stories that branch from a common beginning. Thus cartoons have opened an avenue for experimentation in the study of the rationality of teaching through

\footnotetext{
4 The notion of practical rationality (Herbst \& Chazan 2003) encapsulates the categories of perception and value that organize the stories in the teaching of a mathematics domain, such as geometry or algebra.
} 
story telling. In terms of learning to teach, they allow some degree of immersion in the timeline and timeliness of classroom events and they provide a symbol system with which to speculate about and propose preceding and following actions to those represented.

\subsubsection{Individuality: The ThExpian Casts of Characters}

One important affordance of comics for creating representations of teaching is that they enable the design of representations of different degrees of individuality. This is particularly useful when teacher education classes need to promote conversations about mathematics teaching practice among people who may have attended school, and be placed as interns, in widely different social settings. As McCloud (1993) has argued, nondescript cartoon characters can be transparent-they deflect attention to their actions and talk rather than attract it to themselves. Based on this Herbst \& Chazan (2006) have argued that animations of nondescript cartoon characters can provoke practitioners to project onto them the individualities of those who they know (see also Chazan and Herbst, in review). In this sense animations of cartoon characters can be more effective than video.

In the work of project ThEMaT we have created three casts of characters and used them to represent scenarios of teaching. These casts of characters are all named ThExpians to allude to the notion that they are thespians (actors) involved in a thought experiment. They instantiate different degrees of individuality in human modeling; they are also meant to be like ancient Greece's thespians in that each of them can take different personae in different stories. Thus one cast is called ThExpians $B$ (see Figure 1) and represents teacher and students as blue figures who only differ among themselves by the color of their vest and by their name (a Greek letter). This cast of characters has been used to create geometry classroom animations, slideshows, and comic strips. A second cast is called ThExpians $M$ (see Figure 2) and it represents teacher and students as multicolored figures who differ among themselves by their skin color. This cast has been used to create algebra classroom animations and comic book variations. Both ThExpians B and $\mathrm{M}$ have a limited number of facial expressions they can make by combining eyes, eyebrows, and mouth. They also can make some gestures by using their hands, though their arms and fingers are underdeveloped. The third cast is called ThExpians $P$ (see Figure 3) and it represents teacher and students as humanlike plane figures endowed with articulated arms and fingers; they can also differ from each other by hairstyle, skin color, and shirt design. They have been used in a geometry animation as well as in various comic book representations designed for teacher education and research.

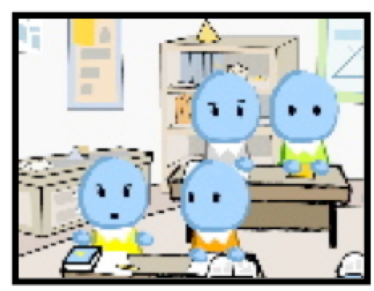

Figure 1. ThExpians B

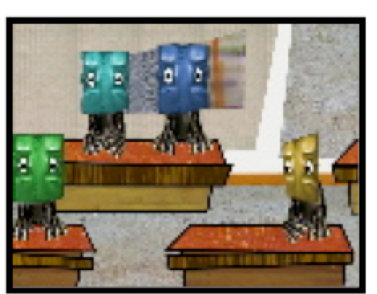

Figure 2. ThExpians M

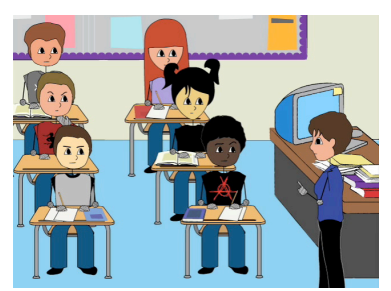

Figure 3. ThExpians $\mathrm{P}$ 


\subsubsection{Temporality: Representing Opportunities for Actions in Time}

The comics genre is particularly useful to represent actions as regards their opportunity and sequence in time and hence raise questions about tactics in teaching. We have implemented the character set ThExpians B in creating more than ten collections of animated movies with voice over that represent stories of geometry instruction. Likewise we have implemented the set ThExpians M in creating five collections of animated movies with voice over that represent stories of algebra instruction. We say collections because, ordinarily, each of those contains more than one video-each collection has a common part, say the beginning of the story, but branches off in alternative ways, for example it may have two or more possible endings. As a set, each collection of alternatives supports the discussion of moments of opportunity as well as of the flow of sequences of actions.

For example, the story Postulates and Theorems on Parallel Lines ${ }^{5}$ starts from a common trunk in which the teacher introduces as a postulate that the corresponding angles between parallel lines cut by a transversal are congruent. She then proves a theorem that asserts that if two parallel lines are cut by a transversal then the alternate interior angles determined by the transversal are congruent. With participation from the class, the teacher then proves that when a transversal cuts two parallel lines, also the same side interior angles are supplementary. At the end of that proof the teacher says that they could just as well have taken as a postulate that alternate interior angles are congruent and prove as a theorem that corresponding angles are congruent. Four endings of this story are proposed to illustrate different ways of seizing this moment and their possible consequences. In version $\mathrm{A}$ the teacher merely makes reference to the postulate used as the choice made by their book's authors and indicates that they could do things differently and choose another postulate; while she makes those comments, students are apparently attending to other concerns. In Version B, the teacher actually writes down the alternative postulate and with the help of the class they prove that when a transversal intersects parallel lines it determines congruent corresponding angles; the class appears attentive and engaged. In Version C, the teacher does the same as in version B but students become disruptive and some rip up their notes from earlier. Finally, in version D the teacher assigns the alternative theorem as extra credit; while one student tries to hash out the proof others are apparently minding unrelated businesses. Neither the main trunk nor any of the endings of those animations necessarily display an ideal kind of teaching or the ideal way of teaching those theorems. Rather, as a set, they bring attention to the pivotal nature of the moment when the teacher recognized the possibility of an alternative postulate and to how different actions taken by the teacher might create context for different reactions by students.

Collections of stories like that one have been used to raise questions about opportunity and tactics with practitioners. The representations have

${ }^{5}$ This and other stories can be watched in http://grip.umich.edu/themat 
appealed to practitioners (Chazan \& Herbst, submitted; Herbst \& Chazan, 2006): In the exchanges that developed in reaction to those rich media artifacts reactions have included proposing alternative pedagogical actions or anticipating possible consequences of particular actions observed.

As noted elsewhere (Herbst and Miyakawa, 2008; Herbst, Nachlieli, and Chazan, accepted) the animated representations of teaching were originally designed as prompts for experienced teachers' discussions. Our aim was to elicit and examine elements of the practical rationality of mathematics teaching (Herbst \& Chazan, 2003). These media have allowed us to do that; in particular since the media form imposes a temporal structure in the experiencing of each story, practitioners' discussions of those stories have often dwelled on tactical decisions made by teachers. But they have also allowed considerations of opportunity and tactics by preservice teachers.

\section{Using Comics-Based Representations of Practice in Methods Courses}

In this section we elaborate on how these comics-based representations of teaching can be of use in preservice teacher education, particularly enabling novices to learn to teach in the context of a methods course. We report not only on the representations of teaching that we created, but also on technologies we have developed to enable the use of those representations in teacher education. We argue that comics can be especially useful in learning to teach, especially so if they are enveloped within IT resources that facilitate the activities involved in that learning. For that argument it may be important to come back to teacher education and the activities that can support learning to teach.

In his contrast between the apprenticeship model and the laboratory model for teacher education, Dewey noted that in the study of practice there are two important, interrelated things to learn-mastery of subject matter from the standpoint of its educational value and use and mastery of the technique of classroom management. While the second was common in Normal school apprenticeship experiences, in order to carve time for the first one, Dewey (1904) recommended a laboratory approach, in which novices could use practice to inquire about matters relevant to that transaction of ideas between teacher and student that is done through teaching. Rather than looking at practice for models to imitate, the laboratory approach looks at practice through the lens of educational theory. Also as Shulman suggests, the demands of practice challenge educational theory to become an aid in judgment and decision-making.

We argue that comics-based representations of teaching can support that kind of laboratory inquiry into practice. In the preparation of future teachers, it is important not only to enable them to notice and interpret events in practice, but also to empower and enable them to conceive pedagogical actions and responses to students' work. Schematic representations of practice such as those realized with cartoon-based comics, can be useful to embody theoretical ideas and promote discussions that integrate 
considerations of theory and of practice. Being leaner in the way they represent individuality these representations may simplify the demands of interpretation, but also being a malleable language to represent practice they may enable the teacher candidate to propose both what to do, as well as observing what is done. The following sections elaborate on this.

\subsection{Learning to see the mathematical work of teaching}

An important goal of teacher preparation is for beginning teachers to learn to see classroom life as a teacher does. In particular, this includes learning to see how mathematical ideas are handled and transacted in and through the unfolding of relationships between teacher and students. Goodwin's (1994) seminal analysis of a controversial legal case articulates starkly ways in which training helps professionals come to see the world as, for example, policemen, and thus differently than the public at large. Similarly, in learning to teach, teachers learn to see classrooms as teachers do, particularly through noticing students' thinking (Sherin, 2007). A helpful theoretical conception of teaching that could serve as beginning point for preservice teachers' inquiry into practice, one that might help candidates see classrooms as teachers, is provided by Cohen's (in press) description of teaching as an activity that deliberately attends to student learning. Cohen (in press) unpacks what this attentiveness in teaching means by saying that a teacher needs to attend to the representation of subject matter, to the cognition of students, and to classroom discourse as the instructional medium where subject matter learning happens.

How could comics-based representations of teaching constitute a laboratory where that theory could be used to look at practice with the purpose of enabling to act? A key question is how the capacity to "attend" in those ways can be developed and practiced. Exposure (in the form of observation, for example) to cases that demonstrate not only careful attention but also lack of sufficient attention can be useful in developing the disposition to attend to those things. Cases deployed in different media (video, written, or comics) could engage preservice teachers in attending to practice. But comics seem to be especially well suited to engage preservice teachers in parsing the flow of action into deliberate moves: They can render action in a simplified way yet without necessarily naming its pieces (as a written case would do), thus leaving work for the preservice teacher to do.

By looking inside scenarios of practice represented with comics, preservice teachers could notice how the teacher attends to the subject matter, the cognition of the students, or the instructional medium; or how he or she fails to do any of those. An important characteristic of comics is their malleability to represent different ways in which the same work could be done. Thus they can facilitate the work of exploring what attending to student learning can mean by enabling inquiry into various possibilities (some not necessarily exemplar) of how the teacher might or might not attend to subject matter, student cognition, or the instructional medium.

The preceding paragraph exemplifies how one could bring a theoretical perspective on teaching to bear in learning to teach. To make that viable, the 
activities of studying practice need to make room for novices to parse cases (e.g., animations) into selections, and making annotations to those selections. Those annotations may initially be assessments (e.g., whether the teacher is appropriately attending to students' cognitions) but may later be interpretations (e.g., of what those cognitions are). One of the animated stories produced by ThEMaT can help illustrate this. The story The Tangent Circle has been used in the first author's "methods" course to exemplify how a problem might be used to teach a new theorem. A novice could watch the teacher pose the problem of constructing a circle tangent to two intersecting lines at two given points followed by the teacher's calling for volunteers to post their work on the board and this followed by a student's (Alpha) solution to the problem. The actions and decisions of the teacher setting up the task ${ }^{6}$ can be the object of a discussion about attending to the mathematics that could be reached through students' engagement on that task: Arguably, in the way the task is proposed, students might encounter the theorem as an explanation for their incapacity to construct the desired circle; but would students be likely to conjecture the theorem if the task had been set up so that they could succeed in constructing the desired circle?

An important goal of the work of watching The Tangent Circle is for preservice teachers to be able to distinguish those three moments (setting up the task, looking for a student to post work, responding to the work posted) as moments when the teacher can act deliberately and attentively. This way of seeing classroom teaching contrasts with seeing those events under a blanket, passive description (e.g., they were working on tangents, it was a problem-based lesson) or with seeing too much texture (e.g., Alpha walks funny, one kid was sleepy). Animations and other comic based representations can be useful scaffolds for the development of a language of description that provides for such parsing of lessons. Having action parsed into practice-relevant chunks of actions, preservice teachers could relate to those in several ways. For example they could evaluate what they see from perspectives mathematical (e.g., the problem is impossible) or relational (e.g., the teacher put Alpha on the spot). But they could also provide an interpretation of what a student may mean when he says or does something (e.g., Alpha is stretching the circle so that it fits the definition of tangent, or Alpha is not thinking where the center of the circle could be).

\subsection{Exploring tactical decision making by proposing alternative stories}

When observing teaching represented through animations of cartoon characters, teacher candidates could also be involved in creating alternatives-e.g., anticipating and representing what other students could have done, or spelling out what the teacher could have done other than calling on a student to show their work. The manifold of alternatives presented for the animation The Tangent Circle exemplifies many of these considerations.

\footnotetext{
${ }^{6}$ In the main trunk of this story, the teacher gives lines with points of tangency that are not equidistant from the intersection of the lines, thus making the problem unsolvable.
} 
While ThEMaT's original focus was to elicit the rationality of experienced teachers, it is clear that, to the extent that they have been students in schools, have chosen to become teachers, and have had special training in mathematics, preservice teachers also have had some socialization into the rationality of teaching (Lortie 1975). Consequently, they are likely to have categories of perception and appreciation with which they may evaluate events in these animations (Bourdieu, 1998; Herbst \& Chazan, 2003). With more specific framing, we have also used the animations in courses for preservice teachers. They have been useful in particular as materials to attend to and conceive the work of the teacher.

In the story The Tangent Circle the teacher makes use of students' work on the original problem and leads the class through transformations of that problem to the point when she feels entitled to introduce the tangent segments theorem. ${ }^{7}$ To illustrate what it could mean to teach a theorem using a problem we have used a combination of first hand experience with two possibilities for the original diagram given with the problem ${ }^{8}$ and viewing of how the animated class interacted with one of those possibilities to prompt discussions about the relationship between the decisions the teacher could have made in setting up a task and the mathematical work that students might end up involved in. In general, the animations provide a context for observation of teaching that can realize some of the aspirations Dewey (1904) had for the laboratory.

The student should ... observe with reference to seeing the interaction of mind, to see how teacher and pupil react upon each other-how mind answers to mind. (p. 155)

To the extent that we don't assume that the representations will always show exemplary methods (or even exemplary uses of content), these animations have a place in preservice education. They enable the visualization of how a mathematical idea could be embodied in classroom interaction, and how this interaction might conceivably proceed. Within appropriate teacher education tasks, the animations can be a resource for preservice teachers to interpret what students are saying, observe what the teacher is doing, engage in practical argument about teaching, and propose alternative courses of action.

To facilitate this work, we have created a lesson annotation technology tool that permits users (e.g., preservice teachers) to annotate and discuss the animations. This lesson annotation software allows an individual user to select an animation from a list and view it while it streams from the server. The user can stop the video at any time and make a comment that is pegged to the moment in the timeline where the user stopped the video. These comments are posted in a "my comments" window which is linked by

\footnotetext{
${ }^{7}$ The tangent segments theorem says that a circle tangent to two intersecting lines has its points of tangency equidistant from the point of intersection.

${ }^{8}$ These possibilities include to give two intersecting lines with two tangent points, one on each line, that are (1) apparently equidistant to the point of intersection and (2) not equidistant to the point of intersection.
} 
timecodes to the video-thus the user may also click on a timecode in the comments window and get to the point on the video timeline where that comment was made (see Figure 4). The user can make various kinds of comments - these include, of course, making text entries, but also attaching diagrams and slideshows. The user can attach a diagram that they compose at the moment using a provided online drawing tool or a diagram that they drew previously on their preferred drawing tool and saved as jpg file. The user may also attach a slideshow of classroom images that they may sketch using the same cast of characters involved in the animation being annotated. To make this possible we have also developed a lesson sketching software that we describe below. With this lesson sketching software, the user can create slides that depict an alternative course of action that might ensue after a given moment in the animation. And they can peg that slideshow to the moment in the timeline from where that alternative begins (see Figure 5). Thus annotation of lessons may call for consideration of alternative actions. The annotation software enables users to also make comments in an animation-specific forum where they can discuss the movie with others; they can make new comments in the forum or they can take comments they had originally made in their personal "My comments" window and post them in the forum.

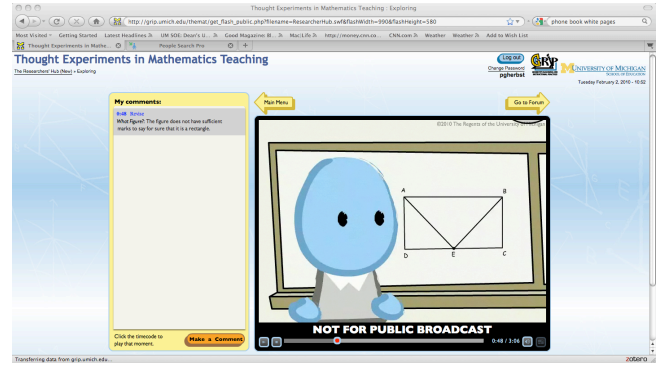

Figure 4. Annotation software

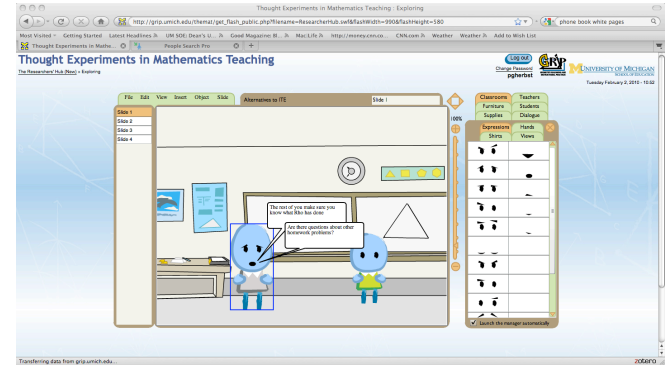

Figure 5. Lesson sketching software

The annotation software has been piloted with a teacher education class. Comments made by students are encouraging in that they show the potential of the animations in enabling thinking about pedagogical alternatives. Note for example how some students responded to Version C of "Parallel lines" (described above).

M: It seems the teacher lacks control because she is doing most of the work with the exception of a few students. This lesson could be done by providing half the class with the 1st postulate, and the other half with the second postulate. They could then work in groups and present their findings in the end of class. This would allow for the students to be more engaged and could also lead to a nice discussion in the end of class.

J: I really like your idea of having half the class work on the first theorem and then the other half working on the second. I believe that this would help the students to understand that a theorem that you proved could also be a postulate for another proof, which hopefully would have prevented their frustration. This method would also get more of the students involved and 
help them all learn how to do the proof without just copying what another student wrote.

The integration of the two pieces of software described in the last two sections (timecode annotation and graphic sketching of alternatives) makes possible for preservice teachers to flesh out those pedagogical ideas as actions of the cartoon teacher. This might inspire them or their readers to conjecture what students might do in response to the alternative actions that they conceive.

\subsection{Imagining Lessons: Rehearsing Classroom Interaction}

A traditional activity in learning to teach is that of planning lessons. Text based forms for lesson planning abound. Most of them enable users to think about the connections between objectives, contents, and the sequence of activities in a lesson. Some of these forms also require the user to estimate the time that each activity in the sequence will take and how they will attend to individual differences. Lesson plan forms are tools to represent and communicate a lesson to others, but their potential as tool for the development of a lesson, to generate what a lesson will consist of, is limited. Developmental feedback can occur when somebody (e.g., an instructor) reads a lesson plan and he or she discovers, for example, that the resources for a task are underspecified or that the goal for a task is unclear, and they recommend revising the plan.

The lesson sketching software alluded to above (see Figure 5) is a tool with which preservice teachers can engage in a self-correcting process in the development of a lesson. We provide here the basic considerations on which we designed this tool. Brousseau's (1997) notion of "adidactical situation" has been key in the design of the functionalities of this software: In an adidactical situation the learner acts on an antagonist "milieu" subsystem. The milieu, which has been designed to enable the learning of a particular idea, but which the learner has to be able to see, at least for some time, as devoid of didactical intention, provides feedback that informs the actions of the learner and thus helps the learner design, or decide on, his or her future actions. It is anticipated that as a result of these interactions the eventual actions of the learner become, at least implicitly, informed by the idea whose learning is at stake.

In thinking about lesson sketching as an alternative to lesson planning we have had in mind two important ideas that preservice teachers need to learn. These are related to the two dimensions of temporality and individuality that we considered earlier when describing video, written cases, and animations as representations of teaching. We propose that the learner of teaching needs to become aware of the temporal demands of the work of teaching, in particular

- A strategic demand, whereby the time spent doing an activity needs to be accountable to the goal of the activity. 
- A tactical demand, whereby each move in the sequence of activities of a lesson needs to create context for its response and this one needs to warrant the following move.

The learner of teaching also needs to become aware of the individual demands of the work of teaching, in particular

- The multivocality (or intellectual diversity) demand, whereby a teacher needs to attend to the many individual voices of a class, who may have diverging responses to the same stimulus.

- The multimodality demand of individual communication, whereby the teacher needs to interpret individual messages that may be communicated in several modalities including not only spoken and written language but also mathematical symbols and diagrams, gestures, body posture, kinesthetics, and facial expression.

How could a milieu be designed so as to support preservice teachers' learning of those demands of teaching? A first hypothesis of such design is to support preservice teachers' active construction of the act of teaching by having them create representations of teaching, much in the same way as learning in academic fields often involves the learner in the creation of artifacts (Pea, 1994). A second hypothesis derives from the consideration that while the learner of teaching may not be so aware of the individuality and temporality demands listed above, they are not empty slates when it comes to having knowledge of teaching. On that account our second hypothesis is that the involvement of preservice teachers in the process of creating and reviewing representations of teaching can summon their incipient understandings of what a mathematics lesson feels like and thus provide the bare bones of a self-correcting, feedback mechanism. Thus, preservice teachers need to be involved not only in creating representations of teaching but also in reviewing, evaluating, and revising them: As they review them and see what they look like, new details of what a lesson could have, based on their experience, become apparent. These considerations have been behind the design of the lesson sketching tool.

To enable an encounter with the temporal demands of teaching we believe it is important to engage preservice teachers in more than lesson planning, but actually in anticipating the development of a lesson through the give and take of human communication. We have in the past done that by engaging preservice teachers in producing and enacting classroom dialogues. This sort of activities was predicated on the hypothesis that having to create and act out lines of dialogue for teacher and student would put the preservice teacher face to face with the tactical demands of classroom interaction, while assessing the dialogue so created against the goals they might have for such teaching would confront them with the strategic demands of classroom interaction.

The demands identified above as multivocality and multimodality are what most clearly call for the development of a tool different than a text editor to create dialogue. Indeed it is often hard for preservice teachers to keep in 
mind that a class contains many students when they are writing a dialogue. They might resort to writing lines spoken by few students or worry little about what students are doing when they are not talking. We envisioned the lesson sketching software to be able to generate graphic slides to represent many students who are present and visible all the time even if they are not speaking all the time. Furthermore, to enable some degree of multimodality, characters designed for this lesson sketching software can make a range of gestures and facial expressions. Different views of the classroom can be chosen and students can be dragged and dropped anywhere in the canvas. The user can edit the content of the board or of the paper on the students' desks by going to a diagram and text editor, or use other web based software to generate strings of mathematical symbols that then they can paste onto the whiteboard or paper. The software allows users to duplicate a slide then make piecemeal adjustments for changes. Finally the software enables the user to play the representation by flipping it slide by slide.

In an ongoing study, ${ }^{9}$ Chia-Ling Chen (under the direction of the first author) has been examining the kinds of anticipation of a lesson that preservice teachers could make when they used in tandem the lesson sketching software and records of actual students' work on the topic of the lesson. The hypothesis is that the combination of information about students' thinking and the lesson sketching software can help preservice teachers attend not only to multivocality and multimodality as general issues but also in regard to the teaching of specific subject matter.

From Chen's analysis of this data we glean that preservice teachers who sketch lessons using these tools are able to attend to the details of the mathematical tasks they are proposing to the class. They refine the tasks by specifying teacher's actions that they think would help students accomplish the tasks. They are specific in how they present the problems, they provide contexts for students to better understand the problems, and they explain the representations used in the problems. In addition, preservice teachers are aware of the need to leave time for students to work, make transitions between tasks, and provide explanations of the connections between tasks. As far as attending to students, when sketching lesson slides, preservice teachers consider students as individuals. This allows preservice teachers to anticipate students' different ways of thinking and emotions, such as students' prior knowledge, learning difficulties, misconceptions, confusion, and excitement.

Those observations have been contrasted with those of a control group in which preservice teachers were asked to anticipate their lessons through interview questions. In this condition the participants have only anticipated the tasks as discrete entities: They did not consider the need to make transitions between tasks or made resources available for students to work through the tasks. With the prompts of interview questions, these preservice

\footnotetext{
${ }^{9}$ Chen, C.-L. (2009, May). Planning ahead in learning to teach: Attending to mathematical interactions with students. Unpublished doctoral dissertation proposal, University of Michigan, Ann Arbor, MI.
} 
teachers were able to anticipate students' possible thinking and reactions. However, they saw students only as a class rather than also as individuals, which might keep them from attending to diverse, concomitant students' thinking or emotions. These contrasting observations help identify the potential of the lesson sketching software as a milieu for teacher learning.

Peers and instructors can combine the activity of lesson sketching with participation in a forum in which preservice teachers post their lessons and receive comments. Such a feature has been piloted in a methods class. The following exchange illustrates the kind of interactions that are possible between a teacher candidate and instructor when they are interacting about an algebra lesson sketched by one teacher candidate (B) and her methods class instructor. The instructor had asked:

What could've happened had the students not come up with answers to Ms. B's question about setting each factor equal to zero? If you were the teacher, how would you have handled this?

In the forum, the instructor elaborated on what could have happened differently than B had anticipated and suggested what he might do Here is where it gets problematic. If the students had not come up with those perfect answers, I think the conversation would have just stopped cold. Lots of blank stares and no hands. If that happened to me I would have tried to reframe the question in a simpler form: something like, "Suppose there are two mystery numbers, and you know their product is zero. What can you be sure of?" And then try to relate that question to the problem on the board.

But then a second teacher candidate, $\mathrm{N}$, proposed another alternative and $\mathrm{B}$ responded.

$\mathrm{N}$ : I might have had them use their graphing calculators to see how the graph looks and explain to me what they see and try to connect some ideas about the zeros. Rewording the question is also helpful maybe asking what is the relationship between the $\mathrm{x}$-axis and the zeros. I don't know if most students would have came up with some of the things that they said. Most of the students who do know the answer rarely share it!

B: That's a good idea, N. I'd probably do that with my own class, but it wasn't something that I thought of in this situation.

A projected development is to create around the activity of sketching lessons a story space-a forum of stories where participants not only post their stories of teaching and comment on others, but also where they can create alternative versions and branches of classroom stories created by other participants.

\section{In conclusion}

We've argued here that comics can be a semiotic resource for the creation of representations of teaching that can be used in teacher education. The main 
contention is that comics realized through nondescript cartoon characters provide a symbol system for representations that are amenable to an active, hands-on study of practice. Obviously, these representations will not replace eventual engagement in real practice where teacher candidates can engage with all the complexity of teaching in real time; but the representations can assist in scaffolding learning about many of those complexities. Furthermore, the simplifications made in creating these semiotic resources may not be well adapted to supporting learning of all aspects of practice (e.g., to learn the way the teacher should be physically present and move in the classroom a completely different environment may be needed). But these representations can be very useful to scaffold much teacher learning. They can help the goal of bringing practice to the university and creating a laboratory, or a virtual setting, where teacher candidates can actively explore the teaching and learning of mathematics. In our argument we explain how these media can capitalize on the advantages of video and written cases, and how software can be designed to enable learning activities that manipulate them. We exemplified this with animated stories of teaching and software created by project ThEMaT.

The stories and the technology to view, annotate, and communicate about stories are powerful tools for helping preservice teachers learn to teach. They can help novices identify key moments and actions in teaching as well as study the encounter of minds in the act of teaching. The lesson sketching software, either as a resource with which to annotate other stories or as a standalone tool to create representations of teaching, is another powerful tool (see also Chieu and Herbst, this issue, for a third application). It can help novices attend to the development of a lesson through time, with many students, and communicating through many modalities. In particular, it can turn learning to teach into something more than description and interpretation: learning to teach may include the actual proposal and practice of possible actions. In that way the study of practice can be useful for preservice teachers to learn to reproduce and improve practice.

\section{References}

Beardsley, L., Cogan-Drew, D., and Olivero, F. (2007). VideoPaper: Bridging research and practice for preservice and inservice teachers. In R. Goldman, R. Pea, B. Barron, and S. Derry (Eds.), Video research in the learning sciences (pp. 479-493). Mahwah, NJ: Erlbaum.

Bourdieu, P. (1990). The logic of practice. Stanford, CA: Stanford University Press.

Bourdieu, P. (1998). Practical reason. Palo Alto, CA: Stanford University Press.

Bourdieu, P. \& Wacquant, L. (1992). An invitation to reflexive sociology. Chicago: University of Chicago Press.

Brousseau, G. (1997). Theory of didactical situations in mathematics: Didactique des Mathematiques 1970-1990. Dordrecht, The Netherlands: Kluwer. 
Brown, J. S., Denning, S., Groh, K., and Prusak, L. (2005). Storytelling in organizations. Burlington, MA: Elsevier.

Carter, K. (1993). The Place of Story in the Study of Teaching and Teacher Education. Educational Researcher, 22, 5-12, 18.

Chazan, D. and Ball, D. (1999). Beyond being told not to tell. For the Learning of Mathematics, 19(2), 2-10.

Chazan, D. and Herbst, P. (submitted). Animations of classroom interaction: Expanding the boundaries of video records of practice. In review at Teachers' College Record.

Clandinin, D. J. and Connelly, F. M. (1996). Teachers' Professional Knowledge Landscapes: Teacher stories, stories of teachers, school stories, stories of schools. Educational Researcher, 25(3), 24-30.

Cohen, D. (in press). Teaching practice and its predicaments.

Collins, A., Brown, J. S., \& Newman, S. E. (1989). Cognitive apprenticeship: Teaching the crafts of reading, writing, and mathematics. In L. Resnick (Ed.), Knowing, learning, and instruction: Essays in honor of Robert Glaser (pp. 453494). Hillsdale, NJ: Erlbaum.

Dewey, J. (1965). The relation of theory to practice in education. In M. Borrowman (Ed.), Teacher education in America: A documentary history (pp. 140-171). New York: Teachers College Press. (Original work published 1904).

Erickson, F. (2004). Talk and social theory. London: Polity.

Feiman-Nemser, S. (1983). Learning to teach. In L. Shulman \& G. Sykes (Eds.), Handbook of teaching and policy (pp. 150-170). New York: Longman.

Feiman-Nemser, S. (2006), A teacher educator looks at democracy and education. In D. Hansen (Ed.), John Dewey and our Educational Prospect: A Critical Engagement with Dewey's Democracy and Education (p. 129-146). Albany, NY: SUNY Press.

Fishman, B. (2007). Fostering community knowledge sharing using ubiquitous records of practice. In R. Goldman et al. (Eds.), Video research in the Learning Sciences (pp. 495-506). Erlbaum.

Goodwin, C. (1994). Professional vision. American Anthropologist, 96(3), 606633.

Grossman, P., Compton, C., Igra, D., Ronfeldt, M., Shahan, E., and Williamson, P. (2009). Teaching practice: A cross-professional perspective. Teachers College Record, 111(9), 2055-2100.

Hall, R. (2000) Videorecording as theory. In A. Kelly and R. Lesh (Eds.), Handbook of research design in mathematics and science education (pp. 647664). Mahwah, NJ: Erlbaum.

Herbst, P. and Chazan, D. (2003). Exploring the practical rationality of mathematics teaching through conversations about videotaped episodes. For the Learning of Mathematics, 23(1), 2-14.

Herbst, P. and Chazan, D. (2006). Producing a viable story of geometry instruction: What kind of representation calls forth teachers' practical rationality? In Proceedings of the $28^{\text {th }}$ Annual meeting of PME-NA. Mérida, Mexico. 
Herbst, P. and Miyakawa, T. (2008). When, how, and why prove theorems: A methodology to study the perspective of geometry teachers. ZDM - The International Journal on Mathematics Education, 40(3), 469-486

Herbst, P., Nachlieli, T., and Chazan, D. (accepted). Studying the practical rationality of mathematics teaching: What goes into installing a theorem in geometry? Cognition and Instruction.

Hiebert, J., Gallimore, R., \& Stigler, J. (2002). A knowledge base for the teaching profession: What would it look like and how can we get one? Educational Researcher, 31(5), 3-15.

Holmes Group. (1990). Tomorrow's Schools: Principles for the Design of Professional Development Schools. East Lansing, MI: Author.

Lampert, M. (2010). Learning teaching in, from, and for practice: What do we mean? Journal of Teacher Education, 61(1-2), 21-34

Lampert, M. and Ball, D. L. (1998). Teaching, Multimedia, and Mathematics: Investigations of Real Practice. New York: Teachers' College Press.

Leinhardt, G. (1990). Capturing craft knowledge in teaching. Educational Researcher 19(2), 18-25.

Lortie, D. (1975). Schoolteacher: A sociological study. Chicago: University of Chicago Press.

McCloud, S. (1993). Understanding comics. New York: Harper.

Merseth, K. (2003). Windows on Teaching Math: Cases of Middle and Secondary Classrooms. New York: Teachers College Press.

Morris, A. K., \& Hiebert, J. (2009). Introduction: Building knowledge bases and improving systems of practice. The Elementary School Journal, 109(5), 429-441.

Nemirovsky, R., Di Mattia, C., Ribeiro, B., and Lara-Meloy, T. (2005). Talking about teaching episodes. Journal of Mathematics Teacher Education, 8(5), 363392.

Pea, R. (1994). Seeing what we build together: Distributed multimedia learning environments for transformative communications. Journal of the Learning Sciences, 3(3), 285-299.

Santagata, R., Zannoni, C., \& Stigler, J.W. (2007). The role of lesson analysis in pres-service teacher education: An empirical investigation of teacher learning from a virtual video-based field experience. Journal of Mathematics Teacher Education, 10, 123-140.

Seago, N., Mumme, J. and Branca, N. (2004). Learning and Teaching Linear Functions: Video Cases for Mathematics Professional Development, 6-10. Portsmouth, NH: Heinemann.

Sherin, M. (2007). The development of teachers' professional vision in video clubs. In R. Goldman, R. Pea, B. Barron, and S. Derry (Eds.), Video research in the learning sciences (pp. 383-395). Mahwah,NJ: Erlbaum.

Shulman, L. (1998) Theory, practice, and the education of professionals. The Elementary School Journal, 98(5), 511-526. 
Herbst et al., Comics-based representations of teaching. Accepted for publication at ZDM-The International Journal on Mathematics Education

Smith, M., Silver, E., and Stein, M. K. (2004), Using Cases to Transform Mathematics Teaching And Learning: Improving Instruction in Algebra. New York: Teachers' College Press.

Schoen, D. (1983). The reflective practitioner. New York: Basic Books.

Schwab, J. J. (1959). The "impossible" role of the teacher in progressive education. School Review, 67, 139-159. 